\title{
State of the Notices
}

\author{
Steven G. Krantz
}

During my five years at the helm of the Notices, we have enjoyed a healthy flow of articles and a vigorous and constructive interaction with authors. At the beginning of my tenure, I expended considerable effort in finding and nurturing new articles, but I can now say that most of our articles originate through author initiative. We are similarly enjoying a modest but steady flow of Opinion pieces and Letters to the Editor. Clearly the Notices is filling an important role as a venue for top-quality mathematics exposition and for discussion of issues facing the mathematics profession.

The articles that we receive exhibit considerable diversity. In addition to articles on education and specialized areas of mathematics, we also receive articles about applications of mathematics to rather surprising areas of human endeavor, we receive articles about the philosophy of mathematics, and we even receive some satirical articles.

In the course of my five-year service, we have created two new columns for the Notices. The first of these, entitled Doceamus (Latin for "Let us teach"), is a column dedicated to teaching issues. Each column is limited to 1,200 words and is selected to focus on some didactic issue of current interest. So far, over forty Doceamus pieces have appeared. The second column that we created is called Scripta Manent (Latin for "Written words endure") and is dedicated to issues in publishing. We conceived the column as a place to discuss the rapid and dramatic changes that electronic media are wreaking on academic publishing. More than twenty pieces have appeared in Scripta Manent.

One of the dramatic events during my time as editor of the Notices was the publication of the article "Principles for implementing a potential solution to the Middle East conflict", by Thomas L. Saaty and H. L. Zoffer. This article suggested means by which mathematical ideas, such as game theory, could be used to help effect a peace in the Middle East conflict. The article struck reviewers

Steven G. Krantz is editor of the Notices. His email address is sk@math.wust 1. edu.

DOI: http://dx.doi.org/10.1090/noti1216 as original, insightful, and certainly unusual. We published it in the November 2013 issue. The article garnered considerable attention and caused a nontrivial amount of tumult. People objected to both the substance and the slant of the article, and some objected even to the graphics. The upshot of this unrest is that AMS President David Vogan appointed a task force to study the matter and to recommend guidelines for handling such situations in the future.

Vogan treated this matter with considerable finesse, and the outcome of the deliberations of the task force was constructive and useful. As a result, it has now become standard procedure for the editor of the Notices to show every incoming Feature and Communication article to the entire Notices Editorial Board. No article can be published without at least two positive reactions from the Board. While the task force presented these procedures only as guidelines, the Board and I were happy to embrace them, and the resulting dialogue among all of the editors has proved to be heartening and helpful.

It must be said that the Notices could not consistently achieve such a high level of quality without decisive support from the AMS staff, especially managing editor Sandy Frost and deputy editor Allyn Jackson. I would particularly like to single out Sandy Frost, who worked on the Notices for two decades. She brought to the job a world of experience, decisive technical expertise, and considerable institutional memory. Sandy retired from the AMS last fall, and her professional contributions and good spirits have been sorely missed. She is replaced by Rachel Rossi, who is working hard to fill a big role. Rachel brings with her fifteen years of book and journal publishing experience, eight years in academic publishing.

Working as editor of the Notices of the AMS has proved to be a rewarding and fascinating task, and one that I view with pride and pleasure. It is delightful to interact with the authors, the readership, and the other editors. I look forward to my remaining time at the Notices. 